\title{
PERCEPÇÃO DE MULHERES \\ EXTRATIVISTAS SOBRE O TRABALHO \\ NA ILHA DE MARAJÓ-PARÁ
}

\author{
Bianca Ferreira Lima* \\ Dalva Maria da Mota**
}

Resumo: $\mathrm{O}$ artigo objetiva analisar por que a atividade extrativista não é considerada como trabalho pelas próprias mulheres, pelos membros do seu grupo doméstico e demais agentes sociais entrevistados quando comparado ao assalariado. A pesquisa foi realizada no povoado Vila Paca, Ilha do Marajó - PA entre 2011 e 2012. A abordagem foi qualitativa. As conclusões mostram que as atividades domésticas e extrativas conformam arranjos de trabalho complementares e flexíveis; o fato do extrativismo ser feito exclusivamente por mulheres influencia no status de não trabalho; e a autonomia para organizar o trabalho influencia nas noções construídas sobre trabalho.

Palavras-chave: Mulheres; trabalho assalariado e doméstico; reprodução social.

\section{Perception of women extractive about work in the island of Marajó- Pará}

Abstract : The article aims to analyze why gathering activity is not considered labour when compared to the remunerated work by the gatherer women, the members of your homegroup and other social actors interviewed.. The research was accomplished at thorp Vila Paca, Ilha do Marajó - PA - in 2011 and 2012 and consisted in qualitative approaches. The main conclusion showed that: the alternate between domestic activities and extractivism conforms arrangements of complementary and flexible working; the fact that extractivism is done exclusively by women influences the status

\footnotetext{
* Mestre em Agriculturas Amazônicas e Desenvolvimento Sustentável. E-mail: biaflorestaa@gmail.com.

** Pós-doutora em Antropologia, pesquisadora da Embrapa Amazônia Oriental, bolsista de produtividade do CNPq. E-mail: dalva@cepatu.embrapa.br. Recebido em: 27/11/2015 - Aceito em: 13/04/2016.
} 
$|90|$

Percepção de mulheres extrativistas...

of not working and the autonomy to organize the work influences the built notions about work.

Keywords: Women; wage work and domestic; social reprodution.

Percepción de las mujeres extractivas acerca del trabajo en la isla Marajó - Pará

Resumen: El artículo objetiva analizar por qué el trabajo de las mujeres no es considerado trabajo por los actores sociales involucrados en la investigación en comparación con el asalariado. La encuesta se realizó en la localidad de Vila Paca, Isla de Marajó - PA - en los años 2011 y 2012 y consistió en enfoques cualitativos. Las principales conclusiones sugieren que: la alternancia entre las tareas domesticas y extractiva ajusta acuerdos de trabajo complementarios y flexibles; el hecho de que la extracción se realiza exclusivamente por las mujeres y influyen en el "status" de no trabajo; y la autonomía para organizar el trabajo tiene influenza en las nociones de trabajo.

Palabras clave: Mujeres; trabajo asalariado y doméstico; reproducción social.

\section{1 - Introdução}

Os estudos que tratam da relação entre trabalho e gênero no extrativismo são raros no Norte do Brasil, corroborando com a percepção de que o debate acadêmico tem dado maior ênfase às mulheres agricultoras. A desproporcionalidade se acentua porque boa parte dos estudos sobre estas últimas foram realizados nas regiões Sul, Nordeste e Sudeste do Brasil (PAULILO, 2000; BRUMER, 2004; SILIPRANDI, 2009; 2006; 2000).

Sobre as mulheres extrativistas, se destacam os trabalhos de Simonian (2001) e de Wolff (1999), que tratam das mulheres castanheiras e seringueiras, analisando como elas têm contribuído para a sobrevivência dos seus grupos domésticos. Segundo a autora, "a continuidade e existência desses grupos estão condicionadas à capacidade de reprodução, o que significa a elaboração de formas de sustentação econômica (SIMONIAN, 2001:18)". Em sua análise, ela aborda aspectos sobre a concepção do tempo social e do tempo individual mediada pela percepção sobre o tempo da natureza. Ela sinaliza que para entender as atividades realizadas na lógica de jornada de trabalho, é preciso compreender o calendário 
agroextrativo, necessariamente marcado pelo tempo de caçar, de pescar, de coletar (frutos, sementes), de capinar, plantar e fazer roça.

Os trabalhos de Maneschy (2001); Maneschy \& Almeida (2002); e Almeida (2002), ao abordarem as mulheres que praticam extrativismo animal, enfatizam a dificuldade de valorização na atividade produtiva por elas realizada, o que acarreta tensões na divisão sexual do trabalho.

No Nordeste os estudos têm enfatizado o processo de luta das quebradeiras de coco babaçu em prol da afirmação de uma identidade coletiva, da conservação do meio ambiente e dos seus modos de vida, bem como a criação de instrumentos legais para garantir os direitos territoriais e, consequentemente, a reprodução social (ANDRADE, 2009; FIGUEIREDO, 2005; VEIGA et. al, 2009; ALMEIDA, 2008; PORRO et al. 2011). Mais recentemente, estudos sobre as catadoras de mangaba e as marisqueiras têm destacado a importância das suas práticas para à conservação da biodiversidade (MOTA et al. 2011). Não obstante, lacunas persistem quanto ao lugar do trabalho nas análises e ganham relevância porque são fortemente influenciados por noções de gênero que nem sempre atribuem o status de trabalho às atividades realizadas pelas mulheres.

Tendo em conta a problemática, o artigo tem como objetivo analisar por que o extrativismo da mangaba, praticado pelas mulheres da Ilha do Marajó - PA, não é considerado (por elas, pelos membros de seus grupos domésticos e pelos demais atores) trabalho quando comparado às atividades assalariadas.

A pesquisa foi realizada no povoado Vila Paca, Salvaterra, Ilha do Marajó - Pará - no período de 2011 e 2012. A metodologia constou de abordagens qualitativas com observações, participação em reunião e entrevistas. Os principais envolvidos foram as mulheres extrativistas de mangaba, os membros de seus grupos domésticos e atores de localidades adjacentes que praticam a atividade.

O artigo está estruturado em quatro partes: i) introdução, ii) o lugar de pesquisa: os espaços socialmente construídos, a partir 
do recorte de gênero e da noção de trabalho; iii) o extrativismo da mangaba, analisando a noção de trabalho neste contexto; e, por fim, iv) as conclusões.

\section{2 - Lugar de pesquisa: os espaços socialmente construídos, a partir do recorte de gênero e da noção de trabalho}

\section{1 - A Vila e os domicílios}

A Vila Paca localiza-se no distrito de Joanes, município de Salvaterra, macrorregião da ilha do Marajó - Pará. É uma localidade recente que tem aproximadamente 30 anos e está constituída por um arruado com seis (6) domicílios, contando com energia elétrica, sistema de abastecimento de água e uma capela católica.

Na Vila Paca, o espaço destinado aos domicílios é de aproximadamente 1.500 metros e abriga as roças e o terreiro de cada grupo doméstico. As casas são na maioria sem reboco e alinhadas às margens de um ramal sem asfalto, que dá acesso às localidades de Água Boa e de Cururu-Grande. As duas últimas localidades são margeadas pela Baía do Marajó, na costa da Ilha, e em períodos de veraneio são locais bastante apreciados pelos turistas, aquecendo a economia local, inclusive com a oportunidade de trabalhos temporários.

Em Vila Paca, a classificação do espaço, conforme Woortmann (1992), reflete os "domínios pertinentes a cada gênero" (p. 3). Ali, as mulheres pertencem à casa, ao terreiro e à roça. Nas casas, a cozinha é uma construção anexa, coberta por telhas de amianto ou palha, e sem paredes. É o espaço escolhido pelas mulheres para conversas durante uma visita quando é servido um café feito no fogão à lenha. As frentes das casas são delimitadas por cercas e portão de madeira. Aos homens pertence o externo à Vila, ou 
seja: o mar e a cidade, sendo esta última, lugar por excelência do trabalho assalariado ${ }^{1}$.

Os espaços de uso comum são de domínio também das mulheres, tanto as mais velhas como as mais jovens. Outros espaços são de uso misto, e não exclusivos dos moradores da vila, como o mangue e o campo da mangaba. Vale ressaltar que o último os homens só utilizam para caçar ou para extrair madeira para a construção de canoas, remos, cercas ou telhados, atividades que são esporádicas.

\section{2 - Família e Grupos Domésticos na Vila Paca}

Segundo a memória oral, a Vila Paca foi fundada pela família Amador, e, a partir do desmembramento dessa família, formaramse seis grupos domésticos, os quais ali viviam no momento da pesquisa. Estende-se à constatação a noção de família como ideia - valor e o grupo doméstico como um agregado de pessoas cuja composição geralmente varia ao longo do ciclo evolutivo e em distintos momentos. "Família, como modelo ideológico, pode ser permanente, enquanto o grupo doméstico pode variar no tempo" (WOORTMANN \& WOORTMANN, 2004: 3).

$\mathrm{Na}$ Vila Paca os moradores afirmam ser parentes e/ou compadres, relações que balizam interações de outra natureza, conforme nos orienta Garcia Jr (1983):

As relações de solidariedade entre os membros de uma mesma família, na produção doméstica, são de outra natureza (econômica e social), e diferem de processos de trabalho em que as relações de produção são estabelecidas por salários (GARCIA JR., 1983: 101).

A população da Vila Paca é de 25 pessoas, agrupadas em quatro tipos de grupos domésticos (Quadro 1):

\footnotetext{
${ }^{1}$ Desse total cinco (20\%) são crianças (na idade entre zero mês até onze anos) e 20 são maiores de 12 anos (80\%) sendo que 36\% têm entre 17 e 39 anos.
} 
QUADRO 1 - Tipologia dos grupos domésticos

\begin{tabular}{|c|c|c|}
\hline Tipo de Grupo Doméstico & Breve Descrição & Total \\
\hline Nuclear & Casal e filhos biológicos & 1 \\
\hline Chefiado por mulheres & $\begin{array}{c}\text { Onde a mulher não tem } \\
\text { um parceiro co-residente, } \\
\text { muitas vezes é mãe } \\
\text { solteira. }\end{array}$ & 1 \\
\hline Extenso & $\begin{array}{c}\text { Além dos pais e das } \\
\text { crianças, coabitam outros } \\
\text { parentes consanguíneos, } \\
\text { podendo ser chefiado } \\
\text { por qualquer um dos } \\
\text { cônjuges }\end{array}$ & 3 \\
\hline Nuclear agregado & $\begin{array}{c}\text { Grupos domésticos } \\
\text { nucleares compartilham o } \\
\text { mesmo espaço (residência } \\
\text { ou estabelecimento), mas } \\
\text { têm orçamento separado }\end{array}$ & 6 \\
\hline
\end{tabular}

Fonte: Pesquisa de campo realizada em 2009/2010.

Em se tratando da chefia dos grupos domésticos, em apenas um caso é o casal que ocupa tal posição. Em três, são as mulheres que desempenham esse papel. Elas são viúvas ou mães solteiras, estudaram até a $3^{\text {a }}$ série do ensino fundamental e desenvolvem suas atividades nas esferas produtivas e reprodutivas. Segundo a classificação de Carvalho (1998), no que diz respeito à chefia domiciliar, em Vila Paca predomina aquela em que há a ausência masculina, uma vez que em três domicílios a chefia feminina é atribuída à viuvez, em dois, à ausência de marido, e, em apenas um domicílio, a chefia é compartilhada entre o casal. Em três domicílios (50\%), o filho caçula, homem, reside na casa da mãe, 
mesmo tendo esposa e filho. Nos outros três domicílios (50\%), os filhos homens caçulas ainda não são casados nem têm filhos. Há dois casos na localidade em que as filhas acima de 17 anos são mães solteiras e moram no domicílio da mãe juntamente com os seus filhos. As mulheres, com apenas uma exceção, trabalham na localidade e em um domicílio. A nora, que ainda não tem filhos, trabalha de modo assalariado como merendeira na escola de outro povoado.

A situação das mulheres jovens que residem no domicílio do grupo doméstico, segundo informaram, não é uma condição invejável por estas dependerem economicamente da mãe e terem pouca liberdade e autonomia, mesmo na criação de seus próprios filhos. Elas afirmam que a situação é transitória, e explicitam o desejo de trabalharem em casas de famílias, como domésticas, situação já foi experimentada por ambas, tendo sido encerrada em virtude da necessidade de retornar à Vila Paca após engravidarem. O fenômeno reforça a constatação de Woortmann \& Woortmann (2004) para os quais:

\begin{abstract}
Mães solteiras e grupos domésticos monoparentais com chefia feminina começaram a surgir com a migração para a cidade. Desaparecendo o controle exercido pela família e pela comunidade, relações sexuais não maritais, mesmo que não frequentes, podem conduzir a monoparentalidade (WOORTMANN \& WOORTMANN, 2004:46).
\end{abstract}

Apesar das avós aceitarem a situação da filha como mãe solteira e contribuírem para a criação dos netos, existe uma tensão velada de ambos os lados. Se por um lado, ajudar na criação dos netos significa, para as avós, o imperativo de obter mais recursos materiais ou dividir os já existentes com mais dois membros no grupo (filha e neto), por outro lado, para as mães significa se submeter aos serviços domésticos, à falta de autonomia nos afazeres e à restrição da liberdade na juventude, pois o "peso" 
de ser mãe solteira, na maioria das vezes, acarreta uma passagem tanto brusca quanto prematura da condição de "jovem" para "mulher madura", independentemente da idade.

Em 1978, Barroso, no seu artigo Sozinhas ou mal acompanhadas: a situação das mulheres chefes de família, já relacionava o fenômeno da chefia feminina às migrações, tanto de homens como de mulheres, e questionava se esse era o fator primordial para a tendência apresentada nos dados censitários das décadas de 50 a 70, para populações de regiões metropolitanas, período em que ocorre uma mudança no perfil da população brasileira, que passa de um país com maior concentração rural para urbana.

Tem-se sugerido que a emergência das famílias chefiadas por mulheres são, em parte, o resultado da migração, sejam de homens que deixam sua mulher e filhos no local de origem, seja de mulheres jovens que migram sozinhas (BARROSO, 1978: 458).

Scott (2010), mais recentemente analisando os dados do FIBGE$^{2}$ (2008), constata que:

a partir da faixa etária de vinte anos, a presença feminina no campo diminui proporcionalmente mais rápido, enquanto os homens apresentam maior tendência de ficar no campo em cada faixa etária sucessiva (SCOTT, 2010:22)

O autor explica que tal fato se deve, em parte, aos adultos que, ao evocarem tal categoria com fins de disciplinar principalmente as mulheres jovens, mais do que para elaborarem novas estratégias cotidianas, terminam por fortalecer a condição de migração das mulheres, que geralmente vão viver exclusivamente de subempregos urbanos (SCOTT, 2010: 29).

Corroborando com Scott (2010), tais questões relativas

\footnotetext{
${ }^{2}$ Fundação Instituto Brasileiro de Geografia e Estatística (FIBGE).
} 
a gênero e geração reproduzem, na Vila Paca, esse cenário conflituoso e de certa forma velado, o qual favorece a migração das mulheres jovens, justificada pela necessidade de estudo, mas que termina com o exclusivo assalariamento como domésticas em casa de famílias e, muitas vezes, com a gravidez e retorno.

\section{3 - Trabalhos, não trabalho dentro e fora da Vila Paca}

\section{1 - Trabalhos recíprocos}

Na Vila Paca os vizinhos e parentes são aliados importantes para a execução de boa parte das tarefas domésticas e produtivas, tais como: o cuidado com as crianças; divisão de alimentos excedentes, geralmente oriundos da caça ou da pesca; compra de remédios; aproveitamento da ida de alguém à cidade para uma carona ou para encomendar algo; mutirões para construção de casa; coleta e fabrico de polpas de frutas; a organização de festejos na localidade; e a fabricação de farinha de mandioca.

Chama a atenção às relações estabelecidas inter grupos domésticos, sustentado, nesse caso, pelos laços de parentesco, vizinhança e compadrio. Sendo assim, as mulheres, por serem as que mais utilizam desta prerrogativa, tanto são sujeitos como objetos do sistema de ajuda mútua e cooperação desenvolvido na localidade, o que permite articular a esfera produtiva e reprodutiva, criando condições, ainda que precárias do ponto de vista do acesso, de saúde, educação e políticas afirmativas, para garantir a sobrevivência dos membros da família.

$\mathrm{Na}$ organização local é atribuição feminina o zelo pelas estruturas comunitárias (limpeza da capela, monitoramento do sistema de água e de energia, as decisões sobre o local adequado para novas construções) e a responsabilidade pelos eventos sociais (ministram aulas de catequese na localidade para as crianças da vila; estabelecem as regras e normas de funcionamento da localidade, como por exemplo, datas e logística para as festas 
de santo; momento de fazer a farinhada), conforme pode ser exemplificado na fala seguinte:

Se surge alguma coisa aqui, somos nós mesmas que resolvemos, a senhora viu que cortaram nossa água aqui por dois dias, se num fosse a D. ir lá em Salvaterra chamar os homens para resolver, a gente ia ficar aqui, naquela situação. Mesmo os homens que moram aqui, tudo trabalham fora, então somos nós mesmas que decidimos negócio de escola, de comida, de fruta, de criação. Vamos pro mangue, vamos atrás de caça, de fazer caieira... Ah! Mana, num tem jeito, de tudo a gente é obrigada a fazer, só Deus mesmo (F. A., 57 anos, moradora da Vila Paca).

A participação dos homens adultos, irmãos e tios nas tarefas que dizem respeito à localidade ocorrem mais explicitamente em momentos em que há necessidade de mediação junto aos negociantes ou comerciantes para aquisição de bens duráveis, tendo em vista que são eles os que estão aptos a conduzir veículos, tanto para o transporte de pessoas como das mercadorias adquiridas. Eles têm também responsabilidade pela socialização das crianças para o trabalho, principalmente do sexo masculino, quando em algumas ocasiões os levam para pescar ou para "ajudar" em alguma tarefa de coleta (caça ou madeira).

Os trabalhos recíprocos alimentam redes de solidariedade e sociabilidade que contribuem para o fortalecimento dos laços sociais. Os moradores amparam-se na retribuição, o que funciona como um tipo de resistência à monetarização de todas as esferas da vida. A circulação é de trabalho e não de dinheiro.

\section{2 - Trabalhos para si e para a família}

Duas ordens de trabalho encontram-se aqui: os desenvolvidos de modo autônomo na Vila e no seu entorno, e aqueles realizados por meio do assalariamento fora da Vila, em outros municípios. $\mathrm{O}$ engajamento em um ou em outro guarda relação com a idade, 
sexo e com o fato de ter ou não ter filhos, exclusivamente para as mulheres.

A maioria dos homens ${ }^{3}$ aptos a trabalhar se ocupa com atividades fora da localidade, dedicando-se à prestação de serviços ou assalariamento, como pedreiros, marceneiros ou pescadores, em outras localidades ou nas cidades de Salvaterra e Belém. A mesma condição é vivenciada pelas mulheres jovens que, sob o argumento da aliança trabalho/estudo, são incentivadas a migrar. A migração é, em tese, uma possibilidade de obtenção de renda e de qualificação. Parte dos salários é destinada às famílias que permanecem nos seus lugares, subsidiando a sobrevivência do grupo doméstico. Entretanto, os desdobramentos da migração de homens e mulheres, para o caso em análise, são bem diferentes. Das entrevistadas, três mulheres chefes de domicílios são irmãs e viveram parte da juventude em Belém, onde trabalhavam como domésticas em casa de família. Duas delas retornaram após o casamento com pessoas da região, e uma permaneceu em Belém até ficar viúva, ocasião que a fez voltar para fixar residência junto à família. As filhas mais velhas de duas dessas mulheres seguiram a mesma trajetória, trabalhando de empregada doméstica em Belém. Entretanto, retornaram para Vila Paca após engravidarem. Em ambos os casos não casaram com os pais biológicos das crianças nem têm apoio dos mesmos, e as crianças não conhecem os respectivos pais. Diante da situação, os membros dos grupos domésticos se desdobram para garantir a sobrevivência com base nos recursos acessíveis localmente em arranjos que mesclam atividades agroextrativistas e assalariadas.

A experiência de trabalho de homens e mulheres oriundos da Vila Paca permite-nos considerá-la como uma totalidade "imbricada dos atributos dos gêneros masculino e feminino" (SILVA, 2014: 165). Como sugere a autora, ela coloca a "nu as relações assimétricas de gênero" exemplificada pela responsabilidade com os filhos e retorno ao grupo doméstico pelas contingências.

${ }^{3}$ Geralmente os maiores de 17 anos.

Idéias - Rev. Inst. Filos. Ciênc. Hum. UNICAMP, v.7, n.1, p. 89-110, jan/jul. 2016 


\section{4 - O cotidiano do trabalho que não é considerado trabalho}

\section{1 - O dia a dia do trabalho}

A vivência dessas mulheres, suas trajetórias e experiências de trabalho dentro e fora da Vila Paca, aliados ao cotidiano e uso do tempo por essas mulheres e pelos membros de seus grupos domésticos, é um caminho possível para entendermos a noção de trabalho reservado às mulheres na Vila Paca. As suas rotinas alternam atividades entre os afazeres domésticos e os afazeres ao redor da casa. Para elas o dia começa cedo. Às 6 horas da manhã o café já está no fogo, e este é o horário de soltar as galinhas no terreiro, de preparar uma tapioca ou colher uma macaxeira para o desjejum. Depois que todos se alimentam, a maioria dos homens acima de 17 anos vai trabalhar, e elas seguem nos seus afazeres, considerado por elas e pelos demais membros como "serviço das mulheres". Nesse rol de atividades se incluem lavar roupas, lavar louças, varrer a casa, limpar o quintal, alimentar as galinhas e iniciar o preparo dos alimentos para o almoço. Há uma variação nessas atividades matutinas que obedece a um calendário agroextrativista local, pois em épocas da safra da mangaba, do bacuri ou em tempo de mariscar, o primeiro período do dia é reservado para estas atividades. Geralmente isso ocorre no verão local (meses de julho a janeiro).

Quando se tem algo para resolver em Salvaterra, o tempo é cuidadosamente calculado por elas, que deixam "tudo adiantado" para poder pegar o transporte às 9 horas e retornar às onze horas (último transporte do dia). Esses dias são, geralmente, no início de cada mês, quando necessitam ir ao banco receber os benefícios, pagar suas contas e comprar o rancho.

O almoço sempre está pronto por volta das $11 \mathrm{~h} 30 \mathrm{~m}$, pois as crianças da localidade estudam em outro povoado, chamado Pingo D'água, no período da tarde e pegam o ônibus disponibilizado pela prefeitura às $13 \mathrm{~h}$. Essa escola abrange do maternal até a $5^{\mathrm{a}}$ série do Ensino Fundamental. Depois é necessário se matricular em Salvaterra para concluir os Ensinos Fundamental e Médio. Apesar 
de haver outras pessoas aptas a continuar os estudos, apenas um morador o fez. As chefes de família que mais estudaram, cursaram até a terceira série do ensino fundamental.

Os homens que saem para trabalhar em Salvaterra ou em outros povoados, também retornam para almoçar em casa e geralmente são eles que trazem a "mistura" (peixe, carne, frango, caranguejo, camarão) para compor a refeição.

Depois do almoço, quando as crianças e os homens não estão na localidade, e depois de uma rápida descansada, as mulheres organizam a cozinha e realizam atividades diversificadas, todas voltadas para a manutenção do domicílio ou da localidade. Entre essas atividades destacam-se a busca de lenha para fazer carvão, a capina do roçado que fica nos fundos da casa, a coleta de algumas frutas no quintal (caju, limão, manga, coco, graviola, entre outras) e a queima do lixo, ou mesmo a caça de pequenos e médios animais, como tatu, paca, que circulam pelo campo da mangaba. Cumpre ressaltar que essas atividades variam no decorrer do ano, uma vez que estão diretamente relacionadas às duas estações locais, o verão e o inverno.

Ao entardecer, as mulheres colocam as galinhas no poleiro, recolhem as roupas do varal, tomam seus banhos, se visitam para colocar a conversa em dia e combinam alguma atividade conjunta para o dia seguinte, quando é o caso. Servem o jantar por volta das $19 \mathrm{~h}$ e logo após vão assistir ao noticiário e às novelas. Após a última novela, todos já estão em suas redes prontos para dormir, horário em que só se ouve os latidos dos cachorros.

Sobre o lugar dessas mulheres, em se tratando do trabalho, cabe destacar que elas permanecem predominantemente na esfera doméstica, mesmo quando trabalhavam em casas de família em Belém. Constatamos que elas não participam e nunca participaram de nenhum grupo social organizado (associação, sindicato, movimento social, grupos religiosos). O universo social frequentado pelas mulheres da Vila Paca é o da casa, dos arredores, da localidade e do campo da mangaba. Os momentos de lazer são na Vila Paca e sempre relacionados com algum festejo, no qual elas se divertem, bebem e comem, mas também são responsáveis por 
preparar e servir os alimentos e as bebidas e depois pela limpeza e organização do espaço. Ou quando, como diaristas, trabalham em restaurantes durante o veraneio (mês de julho) na praia de Água Boa ou de Joanes, localidades vizinhas.

\section{2 - Trabalho e não trabalho: porquês}

O conjunto das atividades desenvolvidas pelos moradores da Vila Paca é formado segundo três tipos: 1) domésticas; 2) agroextrativistas e 3) prestação de serviços através do assalariamento. Nos dois últimos tipos há ingressos monetários em boa parte das atividades. Para além das atividades, familiar ou assalariada, outra via de ingressos monetários são os benefícios previdenciários e os programas de políticas públicas (Bolsa Família, Seguro Defeso da Pesca).

Constatamos que as mulheres da Vila Paca participam dos três tipos de atividades, e corroborando com Lima (2006) e Figueiredo (2005); a casa é a principal referência e também é o espaço de domínio das mulheres na Vila Paca, sendo o local onde a maior parte das atividades domésticas é desenvolvida. Os homens dessa localidade se dedicam com maior predominância às atividades assalariadas e vivem a maior parte do tempo fora da localidade.

As mulheres da Vila Paca e os demais membros do grupo doméstico se referem às atividades domésticas como "serviço de mulher" e não atribuem a estas o status de "trabalho". No léxico das mulheres da Vila Paca, o termo "trabalho" tem relação não só com o retorno financeiro da atividade, mas com o fato desta ser executada fora da localidade, de ter atributo profissionalizante, de ter a figura do "patrão/patroa" e pouca autonomia no uso do tempo, Para elas, o termo não necessariamente se relaciona ao esforço físico e à quantidade de horas gastas para execução de determinadas atividades.

Como exemplo, tomemos as seguintes atividades domésticas: limpeza da casa e das roupas; o preparo da alimentação; o cuidado 
com a higiene das crianças e dos mais idosos. Iremos constatar que, a depender do espaço em que esta é realizada, há uma variação em seu status. Ou seja, quando estas são desenvolvidas nas "casas de família dos outros", momento em que as mulheres vendem sua força de trabalho em troca de dinheiro, há a existência da patroa, há horários a cumprir e um atributo profissionalizante - "empregada doméstica" -, esta recebe o status de "trabalho". Todavia, quando as mesmas atividades não garantem a entrada de recursos monetários ao grupo doméstico, são desenvolvidas no espaço doméstico, não há a presença da patroa e há autonomia no uso do tempo, as mesmas passam a ser "serviço de mulher".

Sehá predominância das mulheresnas atividades domésticas, o mesmo pode-se dizer das atividades agroextrativistas, pois elas são as responsáveis pelo extrativismo das frutas - como a mangaba, o bacuri, o tucumã, o murici - e pelo plantio de espécies agrícolas anuais, como milho, mandioca, melancia, maxixe, jerimum e fruteiras, como a goiaba, o caju e a manga. A maior parte da produção extrativa é destinada à comercialização, diferente da produção dos roçados, que é direcionada para o consumo familiar do grupo doméstico ou para trocas e presentes entre a vizinhança.

Os homens pertencentes ao grupo doméstico não participam do extrativismo de frutas ou das atividades do roçado. Estes se dedicam com maior frequência ao trabalho assalariado, de pedreiro ou nos comércios de Salvaterra e da Vila de Joanes. Nesse contexto, para a maior parte dos homens as atividades são ocasionais. Ainda que os mesmos estejam sempre prestando serviços assalariados, não há contratos formalizados para essas atividades, o que não garante a longevidade da mesma. Para além dos serviços assalariados, os homens esporadicamente praticam a pesca em períodos que o assalariamento está em baixa.

A atividade de pesca é realizada tanto por mulheres como por homens e destina-se apenas para alimentação do grupo doméstico, sendo que essa atividade, de acordo com a classificação dos moradores, não é nada invejável. Esse fato pode ser explicado pela falta de preparo, instrumentos e aptidão dos moradores da 
Vila Paca para realizar a atividade em um campo onde a disputa pelos recursos pesqueiros é acirrada e onde há predominância de homens na atividade. Outra razão pode ser pelo fato de existir, com bastante frequência, pescados para venda nos comércios vizinhos ou por ambulantes na própria localidade. Necessitar pescar para os moradores da Vila Paca configura-se como um atestado de "passar necessidades". Contudo, em momentos em que não há alternativas de consumo e falta dinheiro para aquisição da "mistura", as mulheres vão ao mangue coletar caranguejo, mariscar camarão e se atrevem até a colocar redes e realizar a pesca de anzol em busca de peixes para abastecer o grupo doméstico. Na localidade não há área para realização dessa atividade, o que demanda um deslocamento até o povoado de Água Boa para realizar a tarefa, que também não é considerada trabalho.

As atividades assalariadas são ocasionais para a maioria dos moradores da Vila Paca e em apenas um caso uma mulher trabalha com carteira assinada para a prefeitura municipal, exercendo função de merendeira em uma escola do povoado vizinho. Os demais assalariados não têm esta garantia contratual, e geralmente os trabalhos são feitos por "empreitadas". Aos homens é comum esse tipo de acordo informal de trabalho, e na maior parte dos casos eles se dedicam ao ofício de pedreiro em Salvaterra, Joanes ou mesmo em Belém. Outros, mais jovens, prestam serviço esporadicamente em comércios ou em fazendas na região, e quando alguém se refere a estes, a tônica é sempre o fato de que eles estão trabalhando.

Para as mulheres, os trabalhos assalariados geralmente são em casas de família - empregada doméstica e, para as mais jovens, babá - ou nas barracas de praia durante o mês de julho, como faxineira ou cozinheira. As relações contratuais, nesses casos, também são informais e não garantem os direitos trabalhistas devidos. Na época das entrevistas, nenhuma das moradoras ou parentes trabalhava em casa de família como doméstica, apesar de quase todas já terem experimentado tal situação em momentos anteriores.

As múltiplas atividades desenvolvidas pelas mulheres da 
Vila Paca nem sempre garantem a entrada de recursos monetários, mas certamente garante a subsistência de seus grupos domésticos, uma vez que por meio de dinheiro ou de produtos agroextrativistas, da caça ou da pesca, são garantidas as condições necessárias para a sobrevivência da família, tais como alimentação, vestimentas, remédios e algo para o lazer. Os recursos recebidos via políticas sociais, com uma exceção apenas, são a principal fonte de entrada monetária nos grupos domésticos.

\section{Conclusões}

O objetivo do artigo foi analisar por que o trabalho realizado pelas mulheres da Ilha do Marajó-PA não é considerado trabalho quando comparado ao trabalho assalariado - tanto para as mulheres como para os demais atores locais.

Identificamos nesta pesquisa que as mulheres, com a ajuda das crianças, são as principais responsáveis pelo trabalho doméstico e pela mobilização de recursos monetários para garantir a sobrevivência dos seus grupos domésticos. Constatamos a predominância da chefia domiciliar feminina conformada por múltiplos papeis desenvolvidos pelas mulheres. Dessa maneira, conciliam as atividades de casa com o assalariamento, o extrativismo e a agricultura de subsistência.

Considerando as particularidades do debate para os diferentes campos, constatamos de modo geral que as mulheres estão associadas mais predominantemente ao espaço privado do que ao público e a uma posição de "ajuda" ao trabalho do grupo doméstico, mesmo quando trabalham tanto ou mais que os homens. Esse fator termina por desencadear uma "certa subordinação" da esfera da reprodução à produção.

A maioria das mulheres extrativistas da Vila Paca não tem marido, ou porque estes já faleceram ou porque nunca o tiveram. Os homens adultos que residem na Vila Paca trabalham em cidades ou outras localidades da região e pouco interferem na organização social local. O fato dos homens exercerem suas atividades 
produtivas fora da localidade, diferentemente das mulheres, pode estar relacionado às posições de gênero, apresentadas nos estudos sobre sociedades camponesas, cuja divisão tradicional do trabalho reserva o domínio doméstico como espaço da mulher (FIGUEIREDO, 2005). Todavia, nesses tipos de arranjos familiares, os homens contribuem com recursos monetários para complementar a receita no grupo doméstico, no qual eles não têm o papel de provedores.

Analisando a importância atribuída ao extrativismo da mangaba pelos grupos domésticos e demais atores envolvidos na atividade, concluímos que nesta região a atividade é "naturalizada" e nenhuma das etapas (coleta, beneficiamento e comercialização) realizadas pelas mulheres extrativistas recebe o status de trabalho. Concluímos que isso não significa que a atividade não tenha importância aos olhos do grupo doméstico e demais atores, todavia é secundarizada quando se trata de trabalho considerado por eles produtivo. Essa categoria somente é aplicada ao ofício de marretar, isto é, vender a produção fora da localidade.

Constatamos que localmente a preferência das mulheres extrativistas de mangaba é realizar o beneficiamento dos frutos para produção de polpas congeladas, buscando assim uma maior autonomia sobre a produção, uma vez que há maior elasticidade do produto, referente ao preço e ao armazenamento.

Concluímos que as mulheres mais jovens do grupo doméstico realizam a atividade da mangaba junto às mais velhas (mães ou avós) e só fazem porque não têm outra perspectiva de renda. Diferentemente, percebemos que as crianças gostam de acompanhar suas mães e avós na coleta da mangaba, e o fazem como uma forma de socialização na atividade. Constatamos que pouco grau de escolaridade das mulheres extrativistas de mangaba da Vila Paca, aliado à falta de indústrias e fábricas na região, contribui para a dificuldade de acesso aos empregos assalariados, e na maior parte dos casos em que essas mulheres se empregam é em casa de família, como domésticas, sem a garantia dos direitos trabalhistas. 


\section{Bibliografia}

ANDRADE, M. de P. Hoje, a mulher é a estrela - divisão sexual do trabalho guerreiro nas lutas camponesas no Maranhão. In: FERNANDES, Bernardo Mançano, MEDEIROS, Leonilde Servolo de; PAULILO, Maria Ignez (orgs.). Lutas camponesas contemporâneas: condições, dilemas e conquistas. São Paulo: Editora UNESP; Brasília, DF: Núcleo de Estudos Agrários e Desenvolvimento Rural, 2009. V. 2: a diversidade das formas das lutas no campo. 369 p. 223-247.

ALMEIDA, A. W. B de. Terras de quilombo, terras indígenas, "babaçuais livres", "castanhais do povo", faxinais e fundos de pasto: terras tradicionalmente ocupadas. 2. ed. Manaus: PPGSCA - UFAM, 2008.

BARROSO, C. Sozinhas ou Mal Acompanhadas - a situação das mulheres chefes de família. Campos do Jordão: ABEP, v1, p. 457-472, 1978. Disponível em: <http://www.abep.nepo. unicamp.br/docs/anais/pdf/1978/T78V01A15.pdf.> Acesso em: 21 de abril de 2012.

BRUMER, A. Gênero e agricultura; a situação da mulher na agricultura no Rio Grande do Sul. In. Revista Estudos Feministas, Florianópolis, v. 12, n. 1, p. 205-227, 2004.

FIGUEIREDO, L. D. EMPATES NOS BABAÇUAIS. Do espaço doméstico ao espaço público - lutas de quebradeiras de coco babaçu no Maranhão. 2005. Dissertação (mestrado em Agriculturas Familiares Amazônicas e Desenvolvimento Sustentável) Universidade Federal do Pará, Belém.

GARCIA JÚNIOR, A. Terra de trabalho. Rio de Janeiro, Paz e Terra, 1983. (Coleção Estudos sobre o Nordeste; v. 8).

LIMA, B. F. Vida e trabalho: um estudo sobre mulheres extrativistas de mangaba na Ilha do Marajó, Estado do Pará (Dissertação), (mestrado em Agriculturas Familiares Amazônicas e Desenvolvimento Sustentável) - Universidade Federal do 
Pará, Belém.

LIMA, D. de M. A economia doméstica na várzea de Mamirauá. In: ADAMS, C; MURRIETA, R; NEVES, W. (Org.) In: Sociedades Caboclas Amazônicas: Modernidade e Invisibilidade. São Paulo: Annablume, 2006.

MANESCHY, M. C; ALMEIDA, M. P de. Tornar-se pescadora: associações de mulheres e constituição de sujeitos políticos. In: HÈBETTE, J, MAGALHÃES, S. B e MANESCHY, M. C. (Orgs.). No mar, nos rios e na fronteira: faces do campesinato no Pará. BELÉM: EDUFPA, 2002.

MANESCHY, M. C. Múltiplas atividades femininas nas estratégias de reprodução social de famílias de pescadores. In: COSTA, Maria José Jackson (Org.). Sociologia na Amazônia: debates teóricos e experiências de pesquisa. Belém: Editora Universitária UFPA, 2001.

MOTA, D. M da; SCHMITZ, H; SILVA JÚNIOR, Josué Francisco. Conflito e consenso pelo acesso aos recursos naturais no extrativismo da mangaba. Antropolítica. Niterói, n. 31, p. 123146, 2. sem. 2011

PAULILO, M. I. Movimento de Mulheres Agricultoras: Terra e Matrimônio. Cadernos de Pesquisa, Florianópolis- SC, n. 21, p. 1-21, 2000.

SILIPRANDI, E. Mulheres e agroecologia: a construção de novos sujeitos políticos na agricultura familiar. 2009. 291 f. Tese (Doutorado em Desenvolvimento Sustentável)-Universidade de Brasília, Brasília, 2009.

. Ecofeminismo: contribuições e limites para a abordagem de políticas ambientais. Agroecologia e Desenvolvimento Rural Sustentável, Porto Alegre - RS, v. 1, p. 61-71, 2000.

Políticas de Segurança Alimentar e Papéis de Gênero. Revista Brasileira de Agroecologia, v. 1, n. 1 p. 1417-1421, 2006. Disponível em:<http://www.aba-agroecologia.org.br/ojs2/ 
index.php/rbagroecologia/article/view/6139/4455>. Acesso em: 12 de março de 2011.

SILVA, M. A. de M. Camponesas, fiandeiras, tecelãs, oleiras. In: NEVES, D. P; MEDEIROS, L. S de (Organizadoras). Mulheres Camponesas trabalho produtivo e engajamentos políticos. Nitéroi: Alternativa, 2013.

SIMONIAN, L T.L. Mulheres, cultura e mudanças nos castanhais do sul do Amapá. In: Mulheres da Amazônia Brasileira: entre o trabalho e a cultura. - Belém: UFPA/NAEA, 2001.

SCOTT, P. Gênero e Geração em contextos rurais: algumas considerações. In: SCOTT, Parry; CORDEIRO, Rosineide e MENEZES, M (Org). Gênero e Geração em contextos rurais. Ilha de Santa Catarina: Ed. Mulheres, 2010.

VEIGA, I et. al. Povos e Comunidades Tradicionais Demarcando Territórios na Amazônia: uma análise crítica do caso das Quebradeiras de Coco Babaçu. In: 33‥ ENCONTRO ANUAL DA ASSOCIAÇÃO NACIONAL DE PÓS-GRADUAÇÃO EPESQUISA EM CIÊNCIASSOCIAIS, 2009. Caxambu. Anais... GT 4: Conflitos ambientais, processos de territorialização e identidades sociais. Disponível em: $<$ http://www.anpocs.org. br/portal/index.php?option=com_wrapper\&Itemid $=101>$. Acesso em: 5 de junho de 2011.

WOLFF, C. S. Mulheres da Floresta: uma história: Alto Juruá. São Paulo: HUCITEC, 1999.

WOORTMANN, E. F. Da complementaridade à dependência: espaço, tempo e gênero em comunidades "pesqueiras" do Nordeste. Revista Brasileira de Ciências Sociais, n. 18, ano 7. 1992.

WOORTMANN, K \& WOORTMANN, E. F. Monoparentalidade e chefia feminina: conceitos, contextos e circunstâncias. 2004. Disponível em: www.abep. nepo.unicamp.br /XIII encontro/ woortmann.pdf. Acesso em 18 de abril de 2012. 
